\title{
Cryoballoon Ablation for Persistent and Paroxysmal Atrial Fibrillation: Procedural Differences and Results from the Spanish Registry (RECABA)
}

Ermengol Valles ${ }^{1}$, Jesus Jimenez ${ }^{1}$, Julio Martí-Almor ${ }^{1}$, Jorge Toquero ${ }^{2}$, Jose Ormaetxe ${ }^{3}$, Alberto Barrera-Cordero ${ }^{4}$, Arcadi García-Alberola ${ }^{5}$, Jose Manuel Rubio ${ }^{6}$, PABLO MORIÑA-VÁZQUEZ ${ }^{7}$, Carlos Grande ${ }^{8}$, Maria Fe Arcocha ${ }^{9}$, Rafael Peinado ${ }^{10}$, Rocio Cozar $^{11}$, Julio Salvador Hernandez Afonso ${ }^{12}$, Luisa Perez Alvarez ${ }^{13}$, Larraitz Gaztañaga ${ }^{14}$, Angel Ferrero ${ }^{15}$, Ricardo Ruiz Granell ${ }^{15}$, Roger Villuendas ${ }^{16}$, and jesus martinez-alday ${ }^{17}$

${ }^{1}$ Hospital del Mar Institute for Medical Research

${ }^{2}$ Puerta de Hierro University Hospital of Majadahonda

${ }^{3}$ Hospital de Basurto

${ }^{4}$ Hospital Universitario Virgen de la Victoria

${ }^{5}$ Virgen de la Arrixaca University Hospital

${ }^{6}$ Fundacion Jimenez Diaz-UTE

${ }^{7}$ Hospital Juan Ramon Jimenez

${ }^{8}$ Son Espases University Hospital

${ }^{9}$ Hospital de Araba

${ }^{10}$ La Paz University Hospital

${ }^{11}$ Virgen Macarena University Hospital

${ }^{12}$ Hospital Universitario Nuestra Senora de la Candelaria

${ }^{13}$ Complexo Hospitalario Universitario A Coruna

${ }^{14}$ Basurto University Hospital

${ }^{15}$ Quiron Valencia Clinic

${ }^{16}$ Germans Trias i Pujol University Hospital Cardiology Service

${ }^{17}$ Hospital Universitario Basurto Servicio de Cardiología

July 2, 2021

\begin{abstract}
Introduction: Cryoballoon ablation $(\mathrm{CBA})$ has become a standard treatment for paroxysmal atrial fibrillation (PaAF) but limited data is available for outcomes in patients with persistent atrial fibrillation (PeAF). Methods: We analyzed the first 944 patients included in the Spanish Prospective Multi-center Observation Post-market Registry to compare characteristics and outcomes of patients undergoing CBA for PeAF versus PaAF. Results: A total of 944 patients (57.8 \pm 10.4 years; $70.1 \%$ male) with AF (27.9\% persistent) were prospectively included from 25 centers. PeAF patients were more likely to have structural heart disease (67.7 vs $11.4 \%$; $<0.001$ ) and left atrium dilation (72.6 vs $43.3 \%$; $<0.001)$. CBA of PeAF was less likely to be performed under general anesthesia (10.7 vs $22.2 \%$; $<0.001)$, with an arterial line $(32.2$ vs $44.6 \%$; $<0.001)$ and assisted transeptal puncture (11.9 vs $17.9 \%$; $=0.025)$. During an application, PeAF patients had a longer time to $-30^{\circ} \mathrm{C}(35.91 \pm 14.20$ vs $34.93 \pm 12.87 \mathrm{sec} ; \mathrm{p}=0.021)$ and a colder balloon nadir temperature during vein isolation $\left(-35.04 \pm 9.58 \mathrm{vs}-33.61 \pm 10.32^{\circ} \mathrm{C}\right.$; $\mathrm{p}=0.004)$, but received fewer bonus freeze applications $(30.7$ vs $41.1 \% ; \mathrm{p}<0.001)$. There were no differences in acute pulmonary
\end{abstract}


vein isolation and procedure-related complications. Overall, $76.7 \%$ of patients were free from AF recurrences at 15-month followup $(78.9 \%$ in PaAF vs. $70.9 \%$ in PeAF; $=0.09)$. Conclusions: Patients with PeAF have a more diseased substrate, and CBA procedures performed in such patients were more simplified, although longer/colder freeze applications were often applied. The acute efficacy/safety profile of CBA was similar between PaAF and PeAF patients, but long-term results were better in PaAF patients.

\section{Cryoballoon Ablation for Persistent and Paroxysmal Atrial Fibrillation: Procedural Differences and Results from the Spanish Registry (RECABA)}

Ermengol Vallès ${ }^{a}$, Jesús Jiménez ${ }^{\mathrm{a}}$, Julio Martí-Almor ${ }^{\mathrm{a}}$, Jorge Toquero ${ }^{\mathrm{b}}$, José Miguel Ormaetxe ${ }^{\mathrm{cn}}$, Alberto Barrera ${ }^{\mathrm{d}}$, Arcadio García-Alberola ${ }^{\mathrm{e}}$, José Manuel Rubio ${ }^{\mathrm{f}}$, Pablo Moriña ${ }^{\mathrm{g}}$, Carlos Grande ${ }^{\mathrm{h}}$, Maria Fé Arcocha $^{\mathrm{i}}$, Rafael Peinado ${ }^{\mathrm{j}}$, Rocío Cózar ${ }^{\mathrm{k}}$, Julio Hernández ${ }^{\mathrm{l}}$, Luisa Pérez-Alvarez ${ }^{\mathrm{m}}$, Larraitz Gaztañaga ${ }^{\mathrm{c}}$, Angel Ferrero-De Loma-Osorio ${ }^{\circ}$, Ricardo Ruiz-Granell ${ }^{\circ}$, Roger Villuendas ${ }^{\mathrm{p}}$, Jesús Daniel Martínez-Alday ${ }^{\mathrm{cn}}$

Brief title: Cryoballoon ablation for persistent vs paroxysmal atrial fibrillation

${ }^{a}$ H. del Mar. Universitat Autònoma de Barcelona. IMIM. Barcelona. ${ }^{b} \mathrm{H}$. Puerta de Hierro. Majadahonda. ${ }^{\mathrm{c}} \mathrm{H}$. U. Basurto. Bilbao. ${ }^{d} H$. U. Virgen de la Victoria. Málaga. ${ }^{e} H$. C. U. Virgen de la Arrixaca. Murcia. ${ }^{f} H$. U. Fundación Jiménez Díaz. Madrid. ${ }^{\mathrm{g}} \mathrm{H}$. Juan Ramón Jiménez. Huelva. ${ }^{\mathrm{h}}$ H. U. Son Espases. Palma de Mallorca. ${ }^{i}$ H. U. de Araba. Alava. ${ }^{j} H$. U. La Paz. Madrid. ${ }^{k} H$. U. Virgen Macarena. Sevilla. ${ }^{1} H$. U. Nuestra Señora de la Candelaria. Santa Cruz de Tenerife. ${ }^{\mathrm{m} C . H . U . ~ A ~ C o r u n ̃ a . ~ A ~ C o r u n ̃ a . ~}{ }^{\mathrm{n}}$ C. IMQ Zorrotzaure. Bilbao. ${ }^{\circ}$ H. Clínico Universitario de Valencia. Valencia. ${ }^{p} H$. Germans Trias i Pujol. Badalona.

Address for correspondence: Ermengol Vallès, $\mathrm{MD}, \mathrm{PhD}$

Hospital del Mar, Department of Cardiology, Electrophysiology Unit. 25-29 Passeig Marítim, Barcelona 08003, Spain.

E-mail Address:ermengolvalles@mac.com

Funding: This work was supported by Medtronic Ibérica for the statistical analyses

Acknowledgments: We appreciate Roger Fan, MD, Kendra Braegelmann, PhD for assistance in editing.

Total world count : 5334

ClinicalTrials.gov number: NCT02785991

\section{Abstract}

Introduction: Cryoballoon ablation (CBA) has become a standard treatment for paroxysmal atrial fibrillation $(\mathrm{PaAF})$ but limited data is available for outcomes in patients with persistent atrial fibrillation (PeAF).

Methods: We analyzed the first 944 patients included in the Spanish Prospective Multi-center Observation Post-market Registry to compare characteristics and outcomes of patients undergoing CBA for PeAF versus PaAF.

Results: A total of 944 patients ( $57.8 \pm 10.4$ years; $70.1 \%$ male) with AF (27.9\% persistent) were prospectively included from 25 centers. PeAF patients were more likely to have structural heart disease $(67.7$ vs $11.4 \%$; $\mathrm{p}<0.001)$ and left atrium dilation $(72.6 \mathrm{vs} 43.3 \%$; $<<0.001)$. CBA of PeAF was less likely to be performed under general anesthesia (10.7 vs $22.2 \%$; $<<0.001)$, with an arterial line $(32.2$ vs $44.6 \%$; $<0.001)$ and assisted transeptal puncture (11.9 vs $17.9 \% ; \mathrm{p}=0.025)$. During an application, PeAF patients had a longer time to $-30^{\circ} \mathrm{C}(35.91 \pm 14.20$ vs $34.93 \pm 12.87 \mathrm{sec} ; \mathrm{p}=0.021)$ and a colder balloon nadir temperature during vein isolation $\left(-35.04 \pm 9.58\right.$ vs $\left.-33.61 \pm 10.32^{\circ} \mathrm{C} ; \mathrm{p}=0.004\right)$, but received fewer bonus freeze applications $(30.7$ vs $41.1 \% ; \mathrm{p}<0.001)$. There were no differences in acute pulmonary vein isolation and procedure-related complications. Overall, $76.7 \%$ of patients were free from AF recurrences at 15-month follow-up (78.9\% in $\mathrm{PaAF}$ vs. $70.9 \%$ in PeAF; $\mathrm{p}=0.09$ ). 
Conclusions: Patients with PeAF have a more diseased substrate, and CBA procedures performed in such patients were more simplified, although longer/colder freeze applications were often applied. The acute efficacy/safety profile of CBA was similar between PaAF and PeAF patients, but long-term results were better in PaAF patients.

Key Words: Persistent Atrial Fibrillation, Cryoballoon Procedure, Registry

\section{Introduction}

Pulmonary veins (PV) isolation has emerged as the cornerstone of atrial fibrillation (AF) ablation procedures. ${ }^{1}$ Cryoballoon ablation (CBA) has shown comparable results to those obtained by radiofrequency ablation in patients with paroxysmal atrial fibrillation $(\mathrm{PaAF}) \cdot{ }^{2-8}$ Since patients with persistent atrial fibrillation (PeAF) have a more complex cardiac substrate, multiple ablation strategies involving additional ablation beyond PV isolation have been described. However, stand-alone PV isolation has been shown to be non-inferior to more extensive ablation in this type of patient. ${ }^{9}$ This suggests a role for CBA in PeAF patients, but little is known about the characteristics for patient selection and acute procedural outcomes. ${ }^{10}$ We aimed to assess and compare clinical characteristics, anatomical features, procedural differences, complications and outcomes of patients with PeAF and PaAF undergoing CBA.

\section{Methods}

\section{Description of Registry}

The Spanish Registry of Cryoballoon Ablation (RECABA) is a multicenter, prospective, observational postmarket registry including 29 selected sites, sponsored by Medtronic Ibérica. In total, 27 sites enrolled patients during an inclusion period of 2 years and 3 months between September 2016 and January 2019, during which patients were followed according to routine clinical practice.

Ethics Committee approval was obtained according to local legislation. The study was conducted in compliance with the most recent version of the Declaration of Helsinki, Spanish laws and regulations (Royal Decree 1090/2015, Royal Decree 1616/2009, Order SAS/3470/2009 of 16 December). This observational study did not require authorization by the Spanish Agency of Medicines and Medical Devices (AEMPS), as stipulated in Royal Decrees 1090/2015 and 1616/2009, since it is a clinical investigation with CE marked medical devices used in accordance with the clinical purpose of the device (Arctic Front Advance, Medtronic Inc.). The study was assessed and approved by the IRB, Comité Ético de Investigación Clínica de Euskadi (CEIC-E) on May 9, 2016, and by the Ethical Committee of Hospital de Mar, Comité Ético de Investigación Clínica del Consorci Mar Parc de Salut de Barcelona (CEIC-Parc De Salut Mar) on June 21, 2016. All patients signed informed consent before inclusion in the registry.

The aim of the study was to monitor the current use and outcomes of PV ablation with CBA procedures and collect real-world data on CBA procedures in patients with either PaAF or PeAF. Sites with demonstrable experience of the CBA technique (at least 10 procedures a year) were selected. ${ }^{11,12}$ Clinical data were collected at the baseline procedure and at annual follow up through a web based platform from the hospital patient files. Periodic data cleaning was performed to ensure data quality. The primary objective was to evaluate the efficacy of the CBA at 12 months, defined as the absence of clinical recurrences of AF documented in a 12-lead ECG or subclinical recurrences of AF documented by means of Holter monitoring lasting at least 30 seconds. Only AF was considered as an arrhythmia recurrence. Secondary objectives included evaluation of acute procedural endpoints, procedural complications, and utilization of healthcare resources.

\section{Analysis endpoints}

This analysis was performed on the 944 patients (from the first 25 sites) enrolled during the first year of the study. There were no exclusion criteria. Patients were followed according to each center's discretion (which most of the times included 3- and 6-month visits with ECG and 24-hour Holter monitoring), and a 12 month follow-up visit was protocol required. The primary objectives of this subanalysis were to compare clinical characteristics, anatomical features, and procedural differences of patients with PeAF and PaAF undergoing 
CBA procedures. Acute success and 12-month freedom from a [?]30sec recurrence of documented AF after a 90-day blanking period were evaluated. All procedure-related complications over 12 month follow-up were recorded. Early and late complications, including left atrial flutter, were treated as required according to operator discretion. Major adverse cardiac events (MACE) were defined as the following events: acute myocardial infarction, ischemic stroke, cardiac tamponade, atrio-esophageal fistula and death.

\section{Cryoballoon ablation procedure}

Common elements of the CBA procedure have been previously described. In brief, the procedure was performed with the patient under sedation or total anesthesia and under infusion of unfractionated heparin guided by activated clotting time (ACT). A single trans-septal puncture was performed using a long sheath, guided by fluoroscopy and/or transesophageal/intracardiac echocardiography. The transeptal sheath was exchanged over a guidewire for a $15 \mathrm{~F}$ deflectable introducer, and the second-generation cryoballoon (Arctic Front Advance; either the 23- or 28-mm diameter balloon) was introduced together with the inner-lumen circular mapping catheter (Achieve, Medtronic) into the antrum of each PV. Most of the procedures were performed under the guidance of a three-dimensional reconstruction of the left atrium and pulmonary veins, extracted from a pre-procedural cardiac MRI, CT scan, or left atrial angiography. All procedures aimed to achieve both PV entrance and exit block, which was assessed by careful manipulation and stimulation from the Achieve catheter into each pulmonary vein. Patients in AF during the procedure were cardioverted before or after PV isolation depending on operator preference. Regardless of the type of AF, PV isolation alone was performed. No adjunctive ablation was completed other than CTI ablation in case of history of typical flutter.

\section{Statistical Analyses}

Sociodemographic and clinical data were gathered at the patient level, procedural and freeze application data were gathered at the intervention level. Consequently, each cryoapplication was considered individually, and when appropriate, cryoapplication data were aggregated by location or by patient and location. Frequencies and percentages were used to describe categorical variables. Means, medians, standard deviation and interquartile ranges were used to describe continuous variables. For categorical variables, groups of patients or categories were compared using chi-square tests and standardized adjusted residuals were reported to assess deviations from marginal expected frequencies. For continuous variables, t-tests, and ANOVA procedures were used to compare groups, while multiple comparisons were carried one using Bonferroni adjustment. Variance equality was tested using Levene test. When needed, non-parametric tests were used to compare medians. No imputation method was used and missing information was considered lost pair-wise by the combination of variables considered. When comparing prevalence figures (such as complications) observed values were tested against the overall proportional distribution of cases in the comparison groups. An $\alpha=0.05$ nominal significance level was considered for all tests.

\section{Results}

\section{Population characteristics}

We analyzed the first 944 patients included in the RECABA registry. Table 1 shows the clinical and anatomical characteristics of the patient population. Of note $70.1 \%$ of patients were male and mean age was $57.8 \pm 10.4$ years. Only $17.2 \%$ had structural heart disease (SHD). Overall, $27.9 \%$ procedures were performed for PeAF and $5.7 \%$ for repeat ablation patients. Antiarrhythmic drugs (AAD) and anticoagulation were used in $80.3 \%$ and $73.7 \%$ of patients, respectively. Left atrium dilation (area $>20 \mathrm{~cm} 2$ ) was seen in $48.6 \%$ of patients and $15.9 \%$ had a left common PV ostium.

\section{Procedural characteristics}

All patients in the 29 participating centers received a CBA procedure.Table 2 describes the procedural characteristics. Of note, general anesthesia and adjunctive imaging during transeptal puncture (using intracardiac or transesophageal echocardiography) were used only in $18.9 \%$ and $16.3 \%$ of patients, respectively. 
Phrenic nerve function was monitored in $100 \%$ of cases using diaphragmatic pacing. Pulmonary vein potentials were visualized in $59.8 \%$ of $\mathrm{PVs}$ during the ablation. The number of freeze applications per vein was $1.84 \pm 1.07$, mean time to effect (TTE) was $54.4 \pm 37.2$ seconds, and mean minimal temperature (minT) of the balloon was $-48.95 \pm 6.6{ }^{\circ} \mathrm{C}$. Overall, $97.85 \%$ of PVs were acutely isolated. Complications are listed in Table 3, separating adverse events as procedure-related (5.08\%), non-procedure-related (2.64\%), and MACE (acute myocardial infarction, ischemic stroke, cardiac tamponade, atrio-esophageal fistula and death; $0.3 \%$ ). Complications observed during the procedure consisted of 16 patients with transient phrenic nerve injury (resolved by the time of procedure discharge), 10 patients with transient ST segment elevation, 5 patients with phrenic nerve injury unresolved at the time of procedure discharge, 2 patients with pericardial effusion, 1 groin hematoma, 1 hemorrhage requiring transfusion, 1 ventricular tachycardia and 1 femoral vein laceration. Complications observed early after the procedure consisted of 5 patients with groin hematoma, 1 arterial embolism, 1 myocardial infarct, 1 gastric complication and 1 arteriovenous fistula. Patients were discharged at a mean $1.59 \pm 9.46$ days, $65 \%$ on AAD, with no differences between PaFA vs PeFA (69.6\% vs $63.3 \% ; \mathrm{p}=0.072$ ) and $100 \%$ on anticoagulation.

\section{Clinical and anatomical differences between PaAF and PeAF patients}

Variables were compared between groups, and the following were statistically significant (Table 1 ): PeAF was more frequent among males ( 80.1 vs $66.7 \%, \mathrm{p}<0.001)$, and associated with hypertension $(53.8$ vs $44.2 \%$, $\mathrm{p}=0.008$ ), hypercholesterolemia ( 41.9 vs $32.2 \%, \mathrm{p}=0.005)$, structural heart disease $(67.7$ vs $11.4 \%, \mathrm{p}<0.001)$, previous pacemaker implant (6.2 vs $2.7 \%, \mathrm{p}=0.012$ ), alcohol use (28.7 vs $20.9 \%, \mathrm{p}=0.003)$, tobacco use $(16.1$ vs $10.6 \%, 0=0.024)$ and sleep apnea $(17.8$ vs $10.4 \%, \mathrm{p}=0.003)$. PaAF was more frequent among patients with more than 5 years since AF diagnosis arrhythmia $(29.68$ vs $19.84 \%, \mathrm{p}<0.001)$ and in participants who partake in high-intensity exercise with more than $300 \mathrm{~min} /$ week (46.9 vs $32.8 \%, \mathrm{p}=0.002)$. Anticoagulants and beta-blockers were more commonly used prior to the CBA procedure in PeAF patients, (89.6 vs $67.5 \%$ and 76.4 vs $64.2 \%$, respectively, $\mathrm{p}<0.001$ for both). AAD use was more common in PaAF (85.3 vs $67.4 \%$, $\mathrm{p}<0.001$ ), except for amiodarone, which was more often used in PeAF. PeAF was more associated with left ventricle (LV) dysfunction (27.6 vs 3.7\%, p<0.001), LV hypertrophy $(21.4$ vs $10.5 \%, \mathrm{p}<0.001)$ and LA dilation $>20 \mathrm{~cm}^{2}(72.6$ vs $43.3 \%, \mathrm{p}<0.001)$. Interestingly there were no differences in the rate of anatomical variants such as left common ostium.

\section{Procedural differences between PaAF vs PeAF patients}

A number of differences were found between the two types of patients concerning the CBA procedure (Table 2 ). Patients with PaAF were more likely to undergo preprocedural imaging $(70.2$ vs $56.5 \%, \mathrm{p}<0.001)$, to be treated under general anesthesia (22.2 vs $10.7 \%, \mathrm{p}<0.001$ ), to have an arterial line (44.6 vs $32.2 \%, \mathrm{p}<0.001$ ), and to undergo adjunctive monitoring during transseptal puncture $(17.9$ vs $11.9 \%, \mathrm{p}=0.025)$. PaAF were also more likely to receive bonus CBA freeze applications ( 41.1 vs $30.7 \%, \mathrm{p}<0.001$ ), have a waiting time after isolation (29.5 vs $20.2 \%, \mathrm{p}=0.005)$ and have adenosine testing performed ( 5.4 vs $1.6 \%, \mathrm{p}=0.012$ ). Patients with PeAF had a longer time to $-30^{\circ} \mathrm{C}$ during freezing ( $35.91 \pm 14.20$ vs $34.93 \pm 12.87 \mathrm{sec}, \mathrm{p}=0.021$ ), and a colder balloon nadir temperature at vein isolation $\left(-35.04 \pm 9.58\right.$ vs $\left.-33.61 \pm 10.32{ }^{\circ} \mathrm{C}, \mathrm{p}=0.004\right)$. No differences were observed in the acute PV isolation rate (98.12 vs $97.58 \%$ in PaAF vs PeAF, respectively; $\mathrm{p}=0.327$ ) or procedural complications (Table 3 ).

\section{Long term results among PaAF and PeAF}

Fourteen patients were lost during follow-up. Overall, $76.7 \%$ (217/930) of patients did not have a recurrence of AF over 15 month follow-up. PaAF patients had a higher percentage of freedom from AF recurrence than PeAF patients $(78.9 \%$ vs. $70.9 \%$, respectively; $\mathrm{p}=009)$. Kaplan-Meier survival analyses showed significant curves separation $(\mathrm{p}=0.015)$ corresponding to a faster rate of recurrence in PeAF patients, which was more accentuated after 10 months from the CBA procedure (Figure 1 ).

\section{Discussion}

The RECABA prospective registry of outcomes of cryoablation included a mostly young and healthy popu- 
lation, yet almost one third of patients had PeAF and almost half had some degree of LA enlargement. Most procedures were performed without general anesthesia and without adjunctive imaging during the transseptal puncture. Acute and follow-up success rates were high and comparable to those achieved with RF. Finally combined procedural complications, MACE, and late complication rates after cryoballoon ablation were low.

Few studies have analyzed CBA results and complications in patients with PeAF. ${ }^{13-15}$ To our knowledge this is the only $\mathrm{CBA}$ registry comparing procedural differences and dosing parameters between PaAF and PeAF in the general population.

\section{Comparison between PaAF and PeAF patients}

Persistent AF, as expected, was more frequently comorbid to other cardiovascular risk factors, such as hypertension, hypercholesterolemia, and tobacco/alcohol use. It was also associated with LV dysfunction, LV hypertrophy, LA dilation and previous pacemaker implantation. Surprisingly, although PeAF patients had more comorbidities and cardiovascular disease, $\mathrm{PaAF}$ was more frequent among patients with more than 5 years since AF diagnosis. This likely reflects selection bias within the registry and suggests operators prefer to be more aggressive in the interventional management of $\mathrm{PaAF}$ versus $\mathrm{PeAF}$ when the diagnosis has been made late in the evolution of the disease.

\section{Procedural differences between PaAF vs PeAF patients}

A number of procedural parameters reinforce the theory that operators used a more involved approach in patients with $\mathrm{PaAF}$, including: the performance of an advanced preprocedural image technique, the use of general anesthesia, arterial line, and/or advanced imaging during transseptal puncture. This was not only observed in pre-procedural planning techniques, but also during the ablation procedure itself. Patients with $\mathrm{PaAF}$ were more likely to receive bonus applications to the PVs, have a wait time after isolation, and have an adenosine testing performed. It appeared that operators used more adjunctive methods to achieve durable isolation in $\mathrm{PaAF}$ patients, despite longer times to $-30^{\circ} \mathrm{C}$ and colder balloon nadir temperatures to isolate the veins in PeAF patients. The authors speculate longer times to $-30^{\circ} \mathrm{C}$ could be related to a larger pulmonary vein antrum size, resulting in poor balloon occlusion, limiting the cooling effect of the balloon application. Additionally, the fact that more 28-mm cryoballoons were used in patients with PeAF may indicate the intended strategy of creating a wider lesion set in this type of cardiac substrate.

\section{Complications and acute results. Comparison with other registries}

Procedure-related complications have been reported in 5.5 to $9 \%$ of patients undergoing CBA procedures for $\mathrm{PeAF}{ }^{10,15,16,17}$, which is comparable to the complication rate in patients with $\mathrm{PaAF}$. Phrenic nerve injury, mostly transient, has been the most common complication in CBA procedures, as frequent as $6.3 \%$ in initial reports, but has significantly decreased progressively over years. The German Ablation Registry of paroxysmal AF ablation showed an acute success rate similar for CBA and for radiofrequency, around $97.5 \%$ 5 , also with similar complications rate, around 9.3\%. Similarly, the 1STOP Italian registry study observed similar vein isolation and complications rates, but the latter included procedures performed with the firstgeneration cryoballoon. ${ }^{18}$ None of these studies were performed to compare procedural characteristics of patients with PeAF versus PaAF. However, a subanalyses of the 1 STOP ${ }^{18}$ study included 486 patients with PeAF, and showed similar results to our study ( $8 \%$ rate of total complications ).

\section{Long-term results. Comparison with other studies}

Again there is limited evidence regarding follow-up success after CBA in patients with PeAF versus PaAF. CBA to achieve PVI for patients with PeAF has resulted in similar success rates as radiofrequency ablation with a single procedure, with approximately $55-60 \%$ of patients free of arrhythmia recurrences at 1 year follow-up. ${ }^{13,16}$ Patients with $<1$ year of PeAF tend to have even greater AF recurrence-free rates. ${ }^{14}$ Success rates with multiple procedures can reach $75 \%$ at 12 months ${ }^{18}$ and $69 \%$ at 16 months ${ }^{10}$, which is only slightly inferior to the success achieved in PaAF. Overall $76.7 \%$ of patients in our registry were free of AF recurrences at 15 months follow-up and patients with PaAF showed slightly better outcomes than patients 
with PeAF (78.9\% vs. 70.9\% respectively). Long-term success in PeAF patients was higher in our registry than have been previously reported. We believe this could be related to a younger population treated within RECABA (i.e. age of $57 \pm 10$ years in our registry vs $65 \pm 9$ years in STOP Persistent AF Trial ${ }^{15}$ ).

\section{Limitations}

The limitations of this multicenter observational study include potential bias in patient selection, patienttreatment, and the lack of a control group. Nevertheless, possible biases are mitigated by the prospective data collection and predefined data analysis plan. Since we aimed to describe the real-world results achieved in standard clinical practice, in this analysis a minimum procedure per year per center was requested so that the operator's learning curve had been taken into account. All RECABA centers had already established experience with CBA before patient inclusion started; however, it is possible individual operators experiences a learning curve over the study period. The large number of patients included in the present analysis likely balance the possibility of a learning curve bias. Despite the use of CMR in several patients we did not perform a specific study of atrial fibrosis since this kind of study is not available in the majority of participating centers. Similarly measurements of the PV antrum were not systematically performed, therefore we cannot confirm that longer times to $-30^{\circ} \mathrm{C}$ are related to a larger pulmonary vein antrum size. Lastly follow-up was at center's discretion but the big majority of patients received at least 3 visits including 12-lead ECG and at least one $24 \mathrm{~h}$ Holter monitor.

\section{Conclusions}

Patients with PeAF undergoing CBA have more comorbidities and more diseased cardiac substrate. However, CBA procedures performed in patients with PeAF tend to be more simplified, although longer and/or colder freeze applications were frequently observed. The safety profile of CBA was similar for PaAF and PeAF. While acute efficacy is similar, long-term freedom from AF is higher in PaAF than in PeAF, but a high rate of freedom from $\mathrm{AF}$ was also observed in the PeAF cohort, with [?]70\% free from $\mathrm{AF}$ at 15-month follow-up.

\section{Competing interests}

Dr. Toquero is member of the Medtronic European advisory board. Dr. Toquero, Dr. Villuendas and Dr. Cozar have received speaker honorarium from Medtronic. Dr. Peinado has received a research and training grant from Medtronic. Dr. Toquero and Dr. Garcia-Alberola have received educational grant from Medtronic. Dr. Martinez-Alday has received speaker honorarium from Medtronic, Boston and Abbott. Dr. Ferrero has received speaker honorarium from Medtronic and Boston. Dr. Ferrero has received speaker honorarium from Medtronic and Boston

\section{Data availability statement}

The data that support the findings of this study are available from the corresponding author, E.V. with permission of the Medtronic team upon reasonable request.

\section{References}

1. Camm AJ, Lip GY, De Caterina R, Savelieva I, Atar D, Hohnloser SH. et al. 2012 focused update of the ESC Guidelines for the management of atrial fibrillation: an update of the 2010 ESC Guidelines for the management of atrial fibrillation. Developed with the special contribution of the European Heart Rhythm Association. Eur Heart J. 2012 Nov;33(21):2719-47

2. Douglas L Packer, Robert C Kowal, Kevin R Wheelan, James M Irwin, Jean Champagne, Peter G Guerraet et al. Cryoballoon ablation of pulmonary veins for paroxysmal atrial fibrillation: first results of the North American Arctic Front (STOP AF) pivotal trial. J Am Coll Cardiol . 2013 Apr 23;61(16):1713-23 .

3. Gian-Battista Chierchia, Giacomo Di Giovanni, Giuseppe Ciconte, Carlo de Asmundis, Giulio Conte, Juan Sieira-Moret. et al. Second-generation cryoballoon ablation for paroxysmal atrial fibrillation: 1-year followup. Europace . 16(5), 639-44 (2014). 
4. Giacomo DI Giovanni, Kristel Wauters, Gian-Battista Chierchia, Juan Sieira, Moises Levinstein, Giulio Conte et al. One-year follow-up after single procedure Cryoballoon ablation: a comparison between the first and second generation balloon.J Cardiovasc Electrophysiol . 2014 Aug;25(8):834-839

5. Martin Schmidt, Uwe Dorwarth, Dietrich Andresen, Johannes Brachmann, Karl-Heinz Kuck, Malte Kuniss et al. Cryoballoon versus RF ablation in paroxysmal atrial fibrillation: results from the German Ablation Registry. J Cardiovasc Electrophysiol . 25(1), 1-7 (2014).

6. Karl-Heinz Kuck, Alexander Furnkranz, K R Julian Chun, Andreas Metzner ${ }^{3}$, Feifan Ouyang, Michael Schluter et al. Cryoballoon or radiofrequency ablation for symptomatic paroxysmal atrial fibrillation: reintervention, rehospitalization, and quality-of-life outcomes in the FIRE AND ICE trial. Eur Heart J . 37(38): 2858-2865 (2016).

7. Andreas Metzner, Bruno Reissmann, Peter Rausch, Shibu Mathew, Peter Wohlmuth, Roland Tilz et al. One-year clinical outcome after pulmonary vein isolation using the second-generation 28-mm cryoballoon. Circ Arrhythm Electrophysiol . 2014 Apr;7(2):288-92

8. Karl-Heinz Kuck, Josep Brugada, Alexander Furnkranz, Andreas Metzner, Feifan Ouyang, K R Julian Chun et al. Cryoballoon or Radiofrequency Ablation for Paroxysmal Atrial Fibrillation. $N$ Engl J Med . 3 2016 Jun 9;374(23):2235-459.

9. Atul Verma, Chen-yang Jiang, Timothy R Betts, Jian Chen, Isabel Deisenhofer, Roberto Mantovan et al. Approaches to catheter ablation for persistent atrial fibrillation. $N$ Engl J Med . 2015 May 7;372(19):1812-22

10. Hazem Omran, Klaus-Jurgen Gutleben 'Stephan Molatta, Thomas Fischbach, Birgit Wellmann, Dieter Horstkotte et al. Second generation cryoballoon ablation for persistent atrial fibrillation: an updated metaanalysis. Clin Res Cardiol . 2018 Feb;107(2):182-192.

11. Rui Providencia, Pascal Defaye ${ }^{3}$, Pier D Lambiase, Dominique Pavin, Jean-Pierre Cebron, Franck Halimi . et al. Results from a multicentre comparison of cryoballoon vs. radiofrequency ablation for paroxysmal atrial fibrillation: is cryoablation more reproducible? Europace . 2017 Jan;19(1):48-5712

12. Maurizio Landolina, Giuseppe Arena ${ }^{2}$, Saverio Iacopino ${ }^{3}$, Roberto Verlato, Paolo Pieragnoli, Antonio Curni et al. Center experience does not influence long-term outcome and peri-procedural complications after cryoballoon ablation of paroxysmal atrial fibrillation: Data on 860 patients from the real-world multicenter observational project. Int J Cardiol . 2018 Dec 1;272:130-136 13.

13. Giuseppe Ciconte, Luca Ottaviano, Carlo de Asmundis, Giannis Baltogiannis ${ }^{3}$, Giulio Conte, Juan Sieira et al. Pulmonary vein isolation as index procedure for persistent atrial fibrillation: One-year clinical outcome after ablation using the second-generation cryoballoon. Heart Rhythm . 2015 Jan;12(1):60-6

14. Emily N Guhl, Donald Siddoway, Evan Adelstein ${ }^{1}$, Andrew Voigt, Samir Saba, Sandeep K Jain . Efficacy of Cryoballoon Pulmonary Vein Isolation in Patients With Persistent Atrial Fibrillation. J Cardiovasc Electrophysiol . 22016 Apr;27(4):423-

15. Wilber W Su, Vivek Y Reddy ${ }^{2}$, Kabir Bhasin ${ }^{3}$, Jean Champagne ${ }^{4}$, Robert M Sangrigoli, Kendra M Braegelmann et al. Cryoballoon ablation of pulmonary veins for persistent atrial fibrillation: Results from the multicenter STOP Persistent AF trial. Heart Rhythm. 2020 Nov;17(11):1841-1847 16.

16. Claudio Tondo, Saverio Iacopino, Paolo Pieragnoli, Giulio Molon, Roberto Verlato, Antonio Curnis et al. Pulmonary vein isolation cryoablation for patients with persistent and long-standing persistent atrial fibrillation: Clinical outcomes from the real-world multicenter observational project.Heart Rhythm . 2018 Mar;15(3):363-368

17. Kivanc Yalin, Amr Abdin, Evgeny Lyan, Noureddin Sawan, Spyridon Liosis, Christian Elsner. et al. Safety and efficacy of persistent atrial fibrillation ablation using the second-generation cryoballoon. Clin Res Cardiol . 2018 Jul;107(7):570-577 
18. Luigi Padeletti, Antonio Curnis, Claudio Tondo, Maurizio Lunati, Stefano Porcellini et al. Pulmonary Vein Isolation with the Cryoballoon Technique: Feasibility, Procedural Outcomes, and Adoption in the Real World: Data from One Shot Technologies TO Pulmonary Vein Isolation (1STOP) Project. Pacing Clin Electrophysiol . 2017 Jan;40(1):46-5619.

19. Bruno Reissmann, Tobias Plenge, Christian-Hendrik Heeger, Michael Schluter, Peter Wohlmuth, Thomas Fink et al. Predictors of freedom from atrial arrhythmia recurrence after cryoballoon ablation for persistent atrial fibrillation: A multicenter study. J Cardiovasc Electrophysiol. 2019 Sep;30(9):1436-1442

Tables

Table 1. Clinical and Anatomical Characteristics: Paroxysmal vs Persistent

\begin{tabular}{|c|c|c|c|c|}
\hline Variable & $\begin{array}{l}\text { Patients }(\mathrm{n}= \\
944)\end{array}$ & $\operatorname{PaAF}(n=681)$ & $\operatorname{PeAF}(n=263)$ & $\mathbf{P}$ value \\
\hline $\begin{array}{l}\text { Age }(\%) \\
\text { years }>75 \text { years }\end{array}$ & $26.1 \% 2.6 \%$ & $26 \% 2.5 \%$ & $26.3 \% 2.7 \%$ & 0.480 .52 \\
\hline Gender (male) & $70.1 \%$ & $66.7 \%$ & $80.1 \%$ & $<0.001$ \\
\hline Time Since AF & $12.8 \% 21.9 \% 35.6 \%$ & $10.8 \% 22.6 \% 35.7 \%$ & $17.9 \% 20.2 \% 35.5 \%$ & $<0.001$ \\
\hline $\begin{array}{l}\text { Diagnosis: }<1 \\
\text { year } 1-2 \text { years } 2-5 \\
\text { years } 5-10 \text { years } \\
>10 \text { years }\end{array}$ & $18.1 \% 8.8 \%$ & $19.6 \% 10 \%$ & $14.1 \% 5.7 \%$ & \\
\hline $\begin{array}{l}\text { Type of } \\
\text { procedure } \\
\text { (redo) }\end{array}$ & $5.7 \%$ & $6.2 \%$ & $4.2 \%$ & 0.23 \\
\hline $\begin{array}{l}\text { Cardiac heart } \\
\text { failure (HFpEF } \\
\text { or HFrEF) }\end{array}$ & $7.1 \%$ & $2.8 \%$ & $18.3 \%$ & $<0.001$ \\
\hline Hypertension & $46.9 \%$ & $44.2 \%$ & $53.8 \%$ & 0.008 \\
\hline Hypercholesterolem & $134.9 \%$ & $32.2 \%$ & $41.9 \%$ & 0.005 \\
\hline $\begin{array}{l}\text { Diabetes } \\
\text { mellitus }\end{array}$ & $9.1 \%$ & $8.3 \%$ & $10.3 \%$ & 0.19 \\
\hline $\begin{array}{l}\text { Vascular } \\
\text { disease }\end{array}$ & $5.6 \%$ & $5.5 \%$ & $5.7 \%$ & 0.49 \\
\hline Prior stroke & $5 \%$ & $4.6 \%$ & $6.1 \%$ & 0.21 \\
\hline $\begin{array}{l}\text { Presence of } \\
\text { SHD }\end{array}$ & $17.2 \%$ & $11.4 \%$ & $67.7 \%$ & $<0.001$ \\
\hline $\begin{array}{l}\text { Any level of } \\
\text { sport/exercise } \\
\text { practice }\end{array}$ & $42.9 \%$ & $46.9 \%$ & $32.8 \%$ & 0.002 \\
\hline $\begin{array}{l}\text { High level of } \\
\text { alcohol use }\end{array}$ & $23.1 \%$ & $20.9 \%$ & $28.7 \%$ & 0.003 \\
\hline $\begin{array}{l}\text { Any tobacco } \\
\text { use }\end{array}$ & $12.1 \%$ & $10.6 \%$ & $16.1 \%$ & 0.02 \\
\hline $\begin{array}{l}\text { Diagnosed } \\
\text { OSAS }\end{array}$ & $12.5 \%$ & $10.4 \%$ & $17.8 \%$ & 0.003 \\
\hline $\begin{array}{l}\text { Current AAD } \\
\text { use: None Any }\end{array}$ & $19.7 \% 80.3 \%$ & $14.7 \% 85.3 \%$ & $32.6 \% 67.4 \%$ & $<0.001$ \\
\hline
\end{tabular}




\begin{tabular}{|c|c|c|c|c|}
\hline Variable & $\begin{array}{l}\text { Patients }(\mathrm{n}= \\
944)\end{array}$ & $\operatorname{PaAF}(n=681)$ & $\operatorname{PeAF}(n=263)$ & $P$ value \\
\hline $\begin{array}{l}\text { Current AV } \\
\text { Blockade drugs: } \\
\text { Betablockers } \\
\text { Calcium- } \\
\text { antagonists }\end{array}$ & $67.6 \% 6.2 \%$ & $64.2 \% 5.1 \%$ & $76.4 \% 9 \%$ & $<0.0010 .02$ \\
\hline $\begin{array}{l}\text { Current AC } \\
\text { drugs }\end{array}$ & $73.7 \%$ & $67.5 \%$ & $89.6 \%$ & $<0.001$ \\
\hline $\begin{array}{l}\text { Echo LVEF: }<35 \% \\
36-50 \%>50 \%\end{array}$ & $4.6 \% 5.8 \% 89.6 \%$ & $1.1 \% 2.6 \% 96.3 \%$ & $13.6 \% 14 \% 72.3 \%$ & $<0.001$ \\
\hline Echo LVH & $5 \%$ & $10.5 \%$ & $21.4 \%$ & $<0.001$ \\
\hline $\begin{array}{l}\text { Echo LA } \\
\text { dilatation }(>20 \\
\left.\mathrm{cm}^{2}\right)\end{array}$ & $48.6 \%$ & $43.3 \%$ & $72.6 \%$ & $<0.001$ \\
\hline $\begin{array}{l}\text { Dilated LA area: } \\
\text { Mild }\left(21-30 \mathrm{~cm}^{2}\right) \\
\text { Moderate }(31-40 \\
\left.\mathrm{cm}^{2}\right) \text { Severe }(>40 \\
\left.\mathrm{cm}^{2}\right)\end{array}$ & $66.1 \% 26.3 \% 7.5 \%$ & $78 \% \% 17.2 \% \quad 4.8 \%$ & $50 \% 38.8 \% 11.2 \%$ & $<0.001$ \\
\hline $\begin{array}{l}\text { PV anatomy: } \\
\text { Left common } \\
\text { ostium More than } \\
2 \text { right PVs }\end{array}$ & $15.9 \% 8.1 \%$ & $16.4 \% 7.4 \%$ & $14.6 \% 8.8 \%$ & 0.430 .71 \\
\hline
\end{tabular}

AAD: antiarrhythmic drugs; AC: anticoagulant; AF: atrial fibrillation; AV: atrioventricular; HFpEF: heart failure with preserved ejection fraction; HFrEF: heart failure with reduced ejection fraction; LVEF: left ventricle ejection fraction; LA: left atrium; LVH: left ventricle hypertrophy; OSAS: obstructive sleep apnea syndrome; PaAF: paroxysmal atrial fibrillation; PeAF: persistent atrial fibrillation; PV: pulmonary vein; SDU: Standard Drink Unit; SHD: structural heart disease.

${ }^{1}$ High level of alcohol use $>4$ SDU/day (men), $>2$ SDU/day (women)

Table 2. Procedural Characteristics: Paroxysmal vs Persistent

\begin{tabular}{|c|c|c|c|c|}
\hline & $\begin{array}{l}\text { Patients }(\mathrm{n}= \\
\text { 944) }\end{array}$ & $\operatorname{PaAF}(\mathrm{n}=681)$ & $\operatorname{PeAF}(n=263)$ & $\mathbf{P}$ value \\
\hline $\begin{array}{l}\text { Advanced } \\
\text { image } \\
\text { technique }\end{array}$ & $66.4 \%$ & $70.2 \%$ & $56.5 \%$ & $<0.001$ \\
\hline $\begin{array}{l}\text { Anesthesia: } \\
\text { General Anesthesia } \\
\text { Sedation }\end{array}$ & $18.9 \% 81.1 \%$ & $22.2 \% 77.8 \%$ & $10.7 \% 89.3 \%$ & $<0.001$ \\
\hline Arterial line & $41.2 \%$ & $44.6 \%$ & $32.2 \%$ & $<0.001$ \\
\hline $\begin{array}{l}\text { Number of } \\
\text { catheters } \\
\text { (excluding CB): } 1 \\
23>3\end{array}$ & $\begin{array}{l}15.8 \% 49.5 \% 32.4 \% \\
2.3 \%\end{array}$ & $\begin{array}{l}17.4 \% 48.2 \% 32 \% \\
2.4 \%\end{array}$ & $\begin{array}{l}11.9 \% 52.7 \% 33.5 \% \\
1.9 \%\end{array}$ & 0.23 \\
\hline
\end{tabular}




\begin{tabular}{|c|c|c|c|c|}
\hline & $\begin{array}{l}\text { Patients }(\mathrm{n}= \\
\text { 944) }\end{array}$ & $\operatorname{PaAF}(n=681)$ & $\operatorname{PeAF}(n=263)$ & $P$ value \\
\hline $\begin{array}{l}\text { Adjunctive } \\
\text { imaging during } \\
\text { transseptal } \\
\text { puncture }\end{array}$ & $16.3 \%$ & $17.9 \%$ & $11.9 \%$ & 0.02 \\
\hline $\begin{array}{l}\text { Type of assisted } \\
\text { puncture: TEE } \\
\text { ICE }\end{array}$ & $59.9 \% 40.1 \%$ & $62.5 \% 37.5 \%$ & $51.6 \% 48.4 \%$ & 0.26 \\
\hline $\begin{array}{l}\text { Type of phrenic } \\
\text { nerve monitoring: } \\
\text { Palpation } \\
\text { Fluoroscopy } \\
\text { Modified DI }\end{array}$ & $98.6 \% 27.7 \% 23.7 \%$ & $98.3 \% 27.9 \% 24.4 \%$ & $99.2 \% 21.8 \% 21.8 \%$ & 0.05 \\
\hline $\begin{array}{l}\text { Basal procedural } \\
\text { rhythm: Sinus } \\
\text { rhythm Atrial } \\
\text { fibrillation Typical } \\
\text { AFL Atypical AFL }\end{array}$ & $\begin{array}{l}76.7 \% 22.5 \% \quad 1.6 \% \\
0.3 \%\end{array}$ & $\begin{array}{l}92.9 \% \quad 7.4 \% 0.9 \% \\
0.5 \%\end{array}$ & $35 \% 61.5 \% 3.5 \% 0 \%$ & $<0.001$ \\
\hline $\begin{array}{l}\text { Total } \\
\text { procedure time } \\
(\text { min; ave } \pm \text { SD) }\end{array}$ & $117.8 \pm 40.7$ & $117.9 \pm 40.3$ & $117.8 \pm 41.8$ & 0.94 \\
\hline $\begin{array}{l}\text { Dwell LA time } \\
(\mathrm{min} ; \text { ave } \pm \mathrm{SD})\end{array}$ & $78.4 \pm 28.1$ & $78.3 \pm 27.6$ & $78.5 \pm 29.3$ & 0.90 \\
\hline $\begin{array}{l}\text { Fluoroscopy } \\
\text { time (min; ave } \pm \\
\text { SD) }\end{array}$ & $25.8 \pm 17.3$ & $25.6 \pm 16.3$ & $26.9 \pm 19.6$ & 0.30 \\
\hline $\begin{array}{l}\text { Application } \\
\text { time (min; ave } \pm \\
\text { SD) }\end{array}$ & $21.5 \pm 8.2$ & $21.2 \pm 8.0$ & $22.2 \pm 8.7$ & 0.07 \\
\hline $\begin{array}{l}\text { Cryoballoon size: } \\
28 \mathrm{~mm} 23 \mathrm{~mm}\end{array}$ & $92.2 \% 10.6 \%$ & $90.5 \% 12 \%$ & $96.5 \% 7.3 \%$ & 0.001 \\
\hline $\begin{array}{l}\text { Number of PV } \\
\text { treated (ave } \pm \\
\text { SD) }\end{array}$ & $3.98 \pm 0.75$ & $3.95 \pm 0.76$ & $4.04 \pm 0.746$ & 0.08 \\
\hline $\begin{array}{l}\text { Applications } \\
\text { per vein (ave } \pm \\
\text { SD) }\end{array}$ & $1.87 \pm 1.07$ & $1.87 \pm 1.02$ & $1.86 \pm 1.18$ & 0.65 \\
\hline $\begin{array}{l}\text { Time to }-\mathbf{3 0} \mathbf{0} \mathbf{C} \\
\text { (sec; ave } \pm \mathrm{SD} / \\
\text { median) }\end{array}$ & $35.2 \pm 13.3 / 32$ & $34.9 \pm 12.8 / 32$ & $35.9 \pm 14.2 / 33$ & 0.02 \\
\hline PV potentials & $59.8 \% 70.8 \%$ & $59.2 \% 74.7 \%$ & $61.2 \% 56.5 \%$ & 0.280 .090 .009 \\
\hline monitored: & $71.7 \% 61.2 \%$ & $74.4 \% 59.2 \%$ & $65.2 \% 66.2 \%$ & $\begin{array}{lll}0.06 & 0.41 & 0.03\end{array}$ \\
\hline $\begin{array}{l}\text { Total Left com. } \\
\text { ostium LSPV } \\
\text { LIPV RSPV } \\
\text { RIPV }\end{array}$ & $56.6 \% 48 \%$ & $55.7 \% 45.7 \%$ & $58.7 \% 53.8 \%$ & \\
\hline $\begin{array}{l}\text { Time to effect } \\
\text { (sec; ave } \pm \mathrm{SD} / \\
\text { median) }\end{array}$ & $54.4 \pm 37.2 / 44$ & $53.8 \pm 37.7 / 42$ & $56.2 \pm 35.8 / 47$ & 0.18 \\
\hline
\end{tabular}




\begin{tabular}{|c|c|c|c|c|}
\hline & $\begin{array}{l}\text { Patients }(\mathrm{n}= \\
\text { 944) }\end{array}$ & $\operatorname{PaAF}(n=681)$ & $\operatorname{PeAF}(n=263)$ & $\mathbf{P}$ value \\
\hline $\begin{array}{l}\text { Temperature at } \\
\text { TTE }\left({ }^{\circ} \mathrm{C} \text {; ave } \pm\right. \\
\text { SD / median })\end{array}$ & $-34 \pm 10.1 /-36$ & $-33.6 \pm 10.3 /-35$ & $-35 \pm 9.5 /-37$ & 0.004 \\
\hline $\begin{array}{l}\text { Pulmonary vein } \\
\text { isolation \% (ave } \\
\pm \mathrm{SD} \text { ) }\end{array}$ & $97.8 \pm 9.5$ & $98.1 \pm 8.9$ & $97.5 \pm 10.1$ & 0.32 \\
\hline $\begin{array}{l}\text { Application } \\
\text { time per vein } \\
\text { (sec; ave } \pm \text { SD / } \\
\text { median) }\end{array}$ & $338.2 \pm 182.9$ & $\begin{array}{l}335.7 \pm 176.2 / \\
300\end{array}$ & $\begin{array}{l}344.1 \pm 199.1 / \\
263\end{array}$ & 0.24 \\
\hline $\begin{array}{l}\text { Balloon MinT } \\
\left({ }^{\circ} \mathrm{C}\right): \text { ave } \pm \mathrm{SD} / \\
\text { median }\end{array}$ & $-48.9 \pm 6.6 /-48$ & $-48.8 \pm 6.9 /-48$ & $-49.1 \pm 6.8 /-49$ & 0.36 \\
\hline $\begin{array}{l}\text { Balloon } \\
\text { Rewarming } \\
\text { time (sec): ave } \pm \\
\text { SD / median }\end{array}$ & $39.7 \pm 19.6 / 37$ & $39.6 \pm 19.1 / 37$ & $39.7 \pm 20.4 / 36$ & 0.93 \\
\hline $\begin{array}{l}\text { PV with bonus } \\
\text { application }\end{array}$ & $38.2 \%$ & $41.1 \%$ & $30.7 \%$ & $<0.001$ \\
\hline $\begin{array}{l}\text { Waiting time } \\
\text { after PV } \\
\text { isolation }\end{array}$ & $26.9 \%$ & $29.5 \%$ & $20.2 \%$ & 0.005 \\
\hline $\begin{array}{l}\text { Median waiting } \\
\text { time (min) }\end{array}$ & 15 & 15.3 & 16.5 & 0.34 \\
\hline $\begin{array}{l}\text { Adjunctive CTI } \\
\text { ablation }\end{array}$ & $8.6 \%$ & $8.7 \%$ & $7.9 \%$ & 0.67 \\
\hline $\begin{array}{l}\text { Iodinated } \\
\text { contrast }(\mathrm{ml}): \\
\text { ave } \pm \mathrm{SD}\end{array}$ & $56.4 \pm 46$ & $56.8 \pm 46.7$ & $54.7 \pm 44.2$ & 0.57 \\
\hline Adenosine test & $4.3 \%$ & $5.4 \%$ & $1.6 \%$ & 0.01 \\
\hline $\begin{array}{l}\text { Intraprocedural } \\
\text { electrical } \\
\text { cardioversions }\end{array}$ & $28.7 \%$ & $14.1 \%$ & $65.6 \%$ & $<0.001$ \\
\hline Protamine use & $52.9 \%$ & $52.2 \%$ & $54.7 \%$ & 0.50 \\
\hline Z-Suture & $72.7 \%$ & $73.7 \%$ & $70.2 \%$ & 0.28 \\
\hline
\end{tabular}

AFL: atrial flutter; CB: cryoballoon; CTI: cavo-tricuspid isthmus; ICE: intracardiac echography; LA: left atrium; MinT: Minimal temperature; PaAF: paroxysmal atrial fibrillation; PeAF: persistent atrial fibrillation; PV: pulmonary vein, Rewarming time: time from ablation off to balloon deflation; TEE: transesofageal echography; TTE: time to effect.

Table 3. Complications: Paroxysmal vs Persistent 


\begin{tabular}{|c|c|c|c|c|}
\hline & $\begin{array}{l}\text { Patients }(\mathrm{n}= \\
944)\end{array}$ & $\operatorname{PaAF}(n=681)$ & $\operatorname{PeAF}(n=263)$ & $P$ value \\
\hline $\begin{array}{l}\text { Procedure- } \\
\text { related } \\
\text { complications } \\
\text { (n;\%) During } \\
\text { procedure Phrenic } \\
\text { nerve injury } \\
\text { resolved by } \\
\text { discharge } \\
\text { Transient ST } \\
\text { segment elevation } \\
\text { Phrenic nerve } \\
\text { injury unresolved } \\
\text { by discharge } \\
\text { Early after } \\
\text { procedure (<30 } \\
\text { days) Groin } \\
\text { hematoma } \\
\text { Embolism } \\
\text { Myocardial } \\
\text { infarct Gastric } \\
\text { complication } \\
\text { Arteriovenous } \\
\text { fistula }\end{array}$ & $\begin{array}{l}48 ; 5.08 \% 38 ; \\
4.02 \% 16 ; 1.69 \% \\
10 ; 1.05 \% 5 ; \\
0.52 \% 10 ; 1.05 \% \\
5 ; 0.52 \% 1 ; 0.1 \% \\
1 ; 0.1 \% 1 ; 0.1 \% 1 ; \\
0.1 \%\end{array}$ & $\begin{array}{l}31 ; 4.58 \% 25 ; \\
3.69 \% 12 ; 1.77 \% \\
6 ; 0.89 \% 2 ; 0.30 \% \\
6 ; 0.89 \% 4 ; 0.59 \%\end{array}$ & $\begin{array}{l}17 ; 6.49 \% 13 ; \\
4.96 \% 4 ; 1.53 \% 4 ; \\
1.53 \% 3 ; 1.15 \% 4 ; \\
1.53 \% 1 ; 0.38 \%\end{array}$ & $\begin{array}{llll}0.26 & 0.41 & 0.77 \\
0.40 & 0.11 & 0.40 \\
0.68 & - & - & -\end{array}$ \\
\hline $\begin{array}{l}\text { Non procedure- } \\
\text { related } \\
\text { complications } \\
\text { (>30 days) } \\
\text { (n;\%) Left atrial } \\
\text { flutter Other } \\
\text { tachyarrhythmias }\end{array}$ & $\begin{array}{l}25 ; 2.64 \% 17 ; \\
1.80 \% 5 ; 0.52 \%\end{array}$ & $\begin{array}{l}14 ; 2.07 \% 9 ; \\
1.33 \% 3 ; 0.44 \%\end{array}$ & $\begin{array}{l}11 ; 4.20 \% 8 ; \\
3.05 \% 2 ; 0.76 \%\end{array}$ & $\begin{array}{lll}0.07 & 0.08 & 0.11\end{array}$ \\
\hline $\begin{array}{l}\text { Major Adverse } \\
\text { Cardiac Events } \\
\text { (MACE) (n;\%) } \\
\text { (acute myocardial } \\
\text { infarction, ischemic } \\
\text { stroke, cardiac } \\
\text { tamponade, } \\
\text { atrio-esophageal } \\
\text { fistula and death) }\end{array}$ & $3 ; 0.31 \%$ & $2 ; 0.30 \%$ & $1 ; 0.38 \%$ & 0.27 \\
\hline $\begin{array}{l}\text { Total } \\
\text { complications } \\
(\mathrm{n} ; \%)\end{array}$ & $76 ; 8 \%$ & $48 ; 7.09 \%$ & $28 ; 10.69 \%$ & 0.78 \\
\hline
\end{tabular}

PaAF: paroxysmal atrial fibrillation; PeAF: persistent atrial fibrillation.

Figures

Figure 1. 


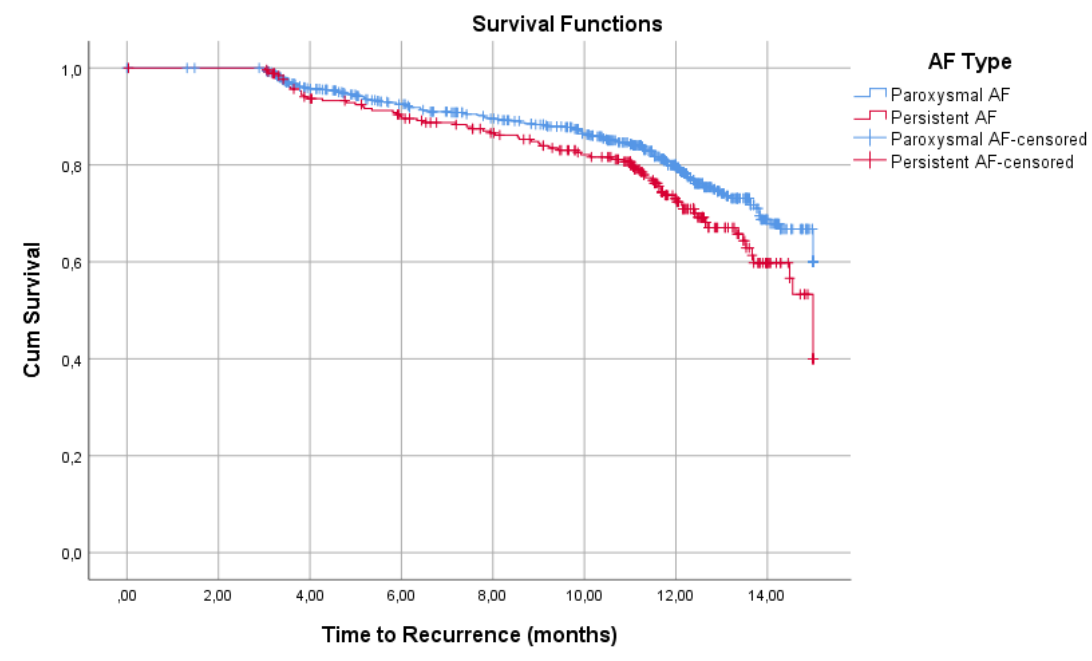

\section{Figure captions}

Figure 1. Recurrences Kaplan-Meier survival analyses. PaAF patients had a higher percentage of freedom from AF recurrence than PeAF patients at 15 months (78.9\% vs. $70.9 \%$, respectively). The curves show significant differences $(\mathrm{p}=0.015)$, which are more accentuated after 10 months. 